This is a preprint of an article accepted for publication in Journal of the American Society for Information Science and Technology copyright @ 2011 (American Society for Information Science and Technology)

\title{
Publication Fees in Open Access Publishing: Sources of Funding and Factors Influencing Choice of Journal
}

\author{
David J Solomon \\ College of Human Medicine, Michigan State University, E. Lansing, MI 48824, \\ Email dsolomon@msu.edu
}

\section{Bo-Christer Björk}

Management and Organization, Hanken School of Economics, Helsinki, Finland, Email bo-christer.bjork@hanken.fi

\begin{abstract}
Open access (OA) journals distribute their content at no charge and use other means of funding the publication process. Publication fees or article processing charges (APC)s have become the predominant means for funding professional OA publishing. We surveyed 1,038 authors who recently published articles in 74 OA journals that charge APCs stratified into seven discipline categories. Authors were asked about the source of funding for the APC, factors influencing their choice of a journal and past history publishing in OA and subscription journals. Additional information about the journal and the authors' country were obtained from the journal website. A total of 429 (41\%) authors from 69 journals completed the survey. There were large differences in the source of funding among disciplines. Journals with impact factors charged higher APCs as did journals from disciplines where grant funding is plentiful. Fit, quality, and speed of publication where the most important factors in the authors' choice of a
\end{abstract}


journal. Open access was less important but a significant factor for many authors in their choice of a journal to publish. These findings are consistent with other research on OA publishing and suggest OA publishing funded through APCs is likely to continue to grow. 


\section{Introduction}

Scientific publishing has undergone two major paradigm shifts. The invention of the printing press revolutionized scholarly publishing, making possible the dissemination of monographs on a much wider scale than was previously possible. In 1665 the Royal Society of London started publishing the Philosophical Transactions which is generally regarded as the original scientific journal (Guédon 2001). The second shift occurred only recently with the emergence of the World wide web, which in a very short time has changed the dominant dissemination medium for scientific journal articles from paper to electronic (Tenopir and King 2000). As a result scientists today mostly retrieve peer reviewed journal articles from web resources, although many still prefer to print out the full texts of interesting articles and read and annotate them on paper.

Due to the move from print publishing to predominantly electronic publications accessible through bundled university licenses most scientists have rapid access to a much greater variety of scholarly journals and articles than before (Ware and Mabe 2009). Yet much of the potential of the web is still left untapped, due to the fact that the business model of scientific publishing has continued to be based on selling content to subscribers, which increasingly tend to be libraries, particularly for electronic versions. While this model was required in the print production era due to the incremental cost of printing and shipping each copy of a journal, it is no longer an absolute necessity in the web environment where 
there is no marginal cost for providing e-access to the content, since publishing costs are more and more concentrated to what Tenopir and King (2000) have labelled first copy costs. Increasingly scientists and publishers have consequently started to question the limited access subscription model and have created new ways of funding scientific journals which allow the content of these journals to be freely accessible. The label Open Access $(\mathrm{OA})$ is nowadays used to describe such journals.

In Open Access the scholarly journal is seen as service provider to authors who wish to get maximal dissemination for their research results. Implicitly journals have traditionally had this function as well. Why else would scholars have been willing to barter away the fruits of their labor for no monetary compensation and even sign very restrictive copyright transfer agreements? With open access this function of providing services to the authors becomes much more explicit.

From around 1993 to 2009 the number of Open Access journals has rapidly risen from a few dozen to more than 5000 (Laakso et al 2011). In the early years most OA journals were funded by individual scholars or groups of scholars who did not charge authors for publishing. This model worked for small journals publishing a few articles per year but doesn't scale well to bigger journals. In addition a number of well-established society journals decided to make the electronic versions of their articles freely available, sometimes with a delay. Portals such as Highwire Press (predominantly used by American society journals) and Scielo (society journals from Latin American countries) have been instrumental in this transition. Starting from around 2000 a number of 
professional Open Access publishers have entered the market using article processing charges (APCs) as their main source of income. BioMed Central and the Public Library of Science are the two earliest and best known of these open access publishers however the number of professional OA publishers using the APC funding model has been growing rapidly over the last decade.

Article processing or publishing charges are not new to scholarly publishing. Many journals have charged authors publication fees for decades. These fees are still quite common in subscription journals for unusually long articles and/or the inclusion of color illustrations. But only now, with electronic only OA journals are APCs becoming the central revenue mechanism for funding the publishing operations.

Starting around 2004 a number of established publishers, led by Springer and Oxford University Press (Bird 2008), have started testing the willingness of scientific authors to pay such charges for individual articles published in otherwise subscription journals. Such an arrangement is now possible in over 2,000 of what are commonly called "hybrid" journals. This model has, however, not become popular, with an overall acceptance rate of only around $2 \%$ (Dallmeier-Tiessen et al 2010). The lack of acceptance of this model is likely due to the generally high level of the payments (usually around 3000 USD) which even exceeds the APC levied by most professional OA journals, and the fact that paying the fee is optional, in order to making the article freely available, and not a condition for being published per se. 
Since an increasing number of highly reputed publishers (Springer, Nature Publishing Group, Sage, and Royal Society) are now launching APC funded OA journals the reaction of potential authors to pay such charges will be very important in deciding if and how rapidly scientific publishing will move towards the OA model. Authors "vote" with their manuscripts and only by getting a sufficient inflow of good quality submissions can OA journals become successful.

Scientific authors when choosing where to submit their manuscripts are making choices in the same way as consumers choosing any other commodity. That is they evaluate the costs and benefits for a particular journal compared to other options. In the past the cost element of a submission has been obscured by the fact that submissions have appeared to be "gratis" to authors. On the other hand the economic value of good articles is considerable for the publisher and what has in fact happened is that the authors have exchanged their manuscripts for the peer review, dissemination and "branding" services provided to them by the publisher. With APC funded OA journals authors will be forced to consider even closer the value they get from a particular journal, especially since there are usually both non-OA and OA alternatives available for each manuscript at hand. All other things being equal OA journals need to be able to offer additional advantages such as accessibility, rapid publication, better topical fit and/or the likelihood of more citations to offset and exceed the negative cost of the APC.

\section{Aim of this study}


- Identify the sources of the funding researcher/scholars are using to fund APC in different disciplines.

- Determine the factors influencing authors' choice of the journal in which they published.

- Find the maximum APC the authors are willing to pay to publish an article in a desired journal.

- Describe the authors in terms of publication experience, discipline, and country to better understand how these factors influence the funding of APCs and the authors' choice of journals in which to publish their research.

\section{Previous research}

There are two previous research tracks which are of relevance for this study. The first track concerns research on how authors in general evaluate scientific journals and how they decide on where to submit. The second track has focused on how scholars evaluate open access journals as potential outlets for their own work.

There are thousands of studies where scientific journals in particular disciplines have been ranked according to their scientific quality or prestige. Nisonger (1999) found 178 published rankings in Library information systems alone. Most of the ranking studies have been based on subjective opinions of scientists in the discipline at hand, sometimes based on very broad surveys and sometimes on the opinions of select groups of leading scientists. Since the 1970s these survey rankings have been supplemented by the citation count based journal impact 
factors published by the ISI. Despite some controversial issues relating to the use of impact factors as a proxy for quality (Anon 2008), they have become a very influential factor in determining author submission choices. Impact factors are used by university administrations, research funders, ministries of education and other decision making bodies as a cost effective way of comparing applicants for posts, research grant applicants as well as the output of research groups and whole universities.

There have been fewer studies, which have looked more in detail into the range of criteria scholars use when deciding where to submit their manuscripts. Ziobrowski and Gibler (2000) for instance studied how authors in the field of real estate chose where to submit manuscripts by sending out questionnaires to authors who in the previous six years had published in three leading journals in the field. They ranked 16 predefined criteria according to a five-point Likert Scale. The highest average score was 4.31 (Author's perception of journal quality) and the lowest 2.01 (Editor knows the author). Based on a factor analysis they reduced the criteria to four major ones: Fair and efficient editorial process, Probability of publication, Quality and Ranking for promotion and tenure (by the employing institution).

Swan and Brown have carried out a number of broad surveys of author preferences $(1999,2004)$. According to their results the two most important factors affecting the submission decision are the readership and the quality of the journal. Readership is not simply a matter of the number of readers. To academics it is often more important to reach the colleagues in the same 
discipline, so that the results can make "a contribution" and hopefully be cited, and the absolute numbers of readers are less important.

Coupé (2004) has also highlighted the fact that authors, if they behave rationally also take into account the risk of rejection, which differs a lot between journals, and what that might entail in terms of delays in getting published.

Nicholas et al (2005) have made a survey of the knowledge of and attitudes towards Open Access of authors who have published articles in ISI indexed journals. Of the 3787 authors who answered the web questionnaire $(3,5 \%$ response rate) two thirds knew about $\mathrm{OA}$ and of these $11 \%$ had ever published an article in an OA journal. The survey results provide a good overview of senior academics attititudes towards OA publishing in the early days, and highlight for instance the regional differences, where around $30 \%$ of authors from Asia and South America had published in OA journals.

Schroter et al $(2005,2006)$ have empirically studied medical journal authors' perceptions of open access journals, using both interview and survey techniques. They found that the factors of importance for deciding on where to submit were impact factor, reputation, readership, speed of publication and the quality of the peer review system. They also asked questions of the willingness to pay APCs and found that the journal quality was the decisive factor.

Björk and Holmström (2006) have proposed a framework ("net value of submission") for the factors authors take into account when choosing where to 
submit. The model includes 29 factors which are aggregated into four groups: infrastructure, readership, prestige and performance. One of the 29 factors is the level of a possible article processing charge, one of the few negative factors in overall balance of factors. This model has later been tested on journals in three different scientific disciplines (Björk and Öörni 2009).

Overall previous research seems to indicate that the "openness" of a journal is only a minor consideration for most authors, when they decide where to submit. Perceived quality and a good topical fit for the manuscript are much more important.

\section{Methodology}

Sampling - Our goal was to draw a sample of authors that broadly reflected scholars/researchers who have recently published articles in OA journals that charge APCs. The Directory of Open Access Journals (DOAJ) served as a source for locating journals from which to sample authors. The DOAJ is widely accepted as the most comprehensive database of OA journals with over 6,500 listed.

Journals were stratified into seven discipline clusters by grouping subsets of the 17 discipline categories used by the DOAJ. Each cluster included disciplines that we believe to have similar academic cultures and availability of support.

\section{Health Sciences, Biology and Life Sciences}


2. Education, Social Sciences, Law and Political Science

3. History and Archaeology, Arts and Architecture, Languages and Literatures

4. Technology, Engineering, Mathematic and Statistics, Computer Science

5. Business and Economics

6. Chemistry, Earth Sciences, Physics and Astronomy

7. Agriculture and Forestry

We attempted to select 15 journals from each discipline cluster listed above.

Where possible, we selected 5 of the 15 journals in each cluster from those with impact factors listed in the Journal Citation Reports for 2009 (JCR 2009). We identified journals in the DOAJ with impact factors using a list developed by Wouter Gerritsma. ${ }^{1}$ The journals we selected were limited to those that published in English, charged APCs and listed the corresponding author's email address. Approximately a fifth of the journals in the DOAJ charge APCs and those tend to be concentrated in the scientific, technical and medical (STM) fields. The majority of these journals are published by few large commercial OA publishers. This limited our ability to get a broad sample of journals that charge APCs across the 7 discipline clusters.

We first attempted to select 5 journals in the JCR 2009 from each cluster. We used a systematic random sampling approach in the STM disciplines where a high percentage of journals charged APCs. In the other clusters we identified as many journals as we could find that had impact factors. 
We then used the DOAJ web site to identify the rest of the journals. We attempted to use a systematic random sampling approach however this did not turn out to be practical. The DOAJ metadata at the time we drew the sample of journals did not include whether a journal charged APCs. This required us to confirm that a selected journal charged APCs by searching the journal web site which was very time consuming. To make the selection process feasible we limited our selection process to commercially published OA journals. We did include a few non-commercial journals which we were able to identify that charged APCS s. In some clusters we were unable to identify 15 journals that charged APCs. In those clusters we included all journals charging APCs that we could locate.

Each journal selected served as a sub-cluster for sampling authors. Where possible we sampled from each selected journal the corresponding authors from 15 articles published in 2010 . We started with the most recently published article and worked backward by date of publication until 15 articles were identified. When authors had published multiple articles, they were only included once and an additional author was selected. If there were less than 15 articles published in 2010 for a given journal, we continued to work backward selecting additional authors who published articles in 2009. In a few cases where journals had been launched in 2010, we included authors who published articles in 2011.

A total of 1,038 corresponding authors who had published articles in 74 journals were asked to participate in the survey. 
Data collection - The survey was developed by the lead author based on the research questions outlined above with the goal of keeping the instrument as short as possible to help increase the response rate. The instrument was reviewed by a number of people with expertise in open access publishing. A copy of the survey can be viewed at:

http://www.openaccesspublishing.org/apc/survey.example.html

Each author was sent an email request to participate in the web-based survey.

A copy of the email used to solicit authors can be viewed at:

http://www.openaccesspublishing.org/apc/survey.request.example.html

Authors who failed to respond within approximately a week were sent a second email request.

Additional data was collected from the journal web site and the DOAJ. The data elements included the journal publisher, ISSN, amount of the APC and discipline of the journal based on what was listed in the DOAJ. For a subset of the journals the APC was based on the number of pages published. In those cases we calculated the actual APC based on the number of pages in the article that the author published in that journal. 
For each article we collected the title, corresponding author's country, their name, email address and either the digital object identifier (DOI) or Uniform resource locator (URL) of the article. These data were merged with the survey responses.

The survey and other data collection procedures were piloted with 123 authors from four journals in medical education. No changes were made in the instrument or procedures for the main study. As such, data from the pilot was included in the analyses. ${ }^{2}$

The statistical significance of the relationship among variables in Tables 2 through 6 below was assessed using Fisher's exact test.

The study protocol was reviewed by the Biomedical and Health Institutional Review Board of the Michigan State University Human Research Protection Program and deemed to be "Exempt" (IRB \# x10-1223). All currency amounts are listed in US Dollars (USD).

\section{Results}

Description the respondents - A total of 429 or just over $41 \%$ of the authors responded to the request to complete the survey. They were located in 65 countries and published articles in 69 journals from 23 publishers. A total of 111 or approximately $26 \%$ of the authors had published articles in journals had impact factors listed in the JCR 2009. A total of 266 or approximately $62 \%$ of the 
authors were from countries where the annual per capita gross national product was greater than $\$ 25,000$ per year in 2008 . These included countries in North America, Western Europe, Japan, Australia and New Zealand. Tables listing the author's country, journal in which they published and the publishers are available in the supporting material.

Although the response rate of $41 \%$ and less than we hoped, it is considerably higher than many of the studies in this area for example Nichols et al., 2005b and Dallmeier-Tiessen, (2010). Additionally, a broad range of authors in terms of discipline, location and the size of the APC paid responded to the survey.

Table 1 provides a breakdown of the total number of articles published over the last five years by the authors in a) subscription journals, b) OA journals that do not charge APCs and c) journals that do charge APCs. The table is based on three questions in the survey asking to indicated the number of article published over the last five years in each of the above categories.

The authors were asked "If there were a journal in which you had a strong desire to publish, what would be the maximum APC you would be willing to pay?" The responses ranged from $\$ 0$ to $\$ 5,000$ USD with an average amount of $\$ 649$ and a standard deviation of $\$ 749$. We suspect that many of the authors interpreted the question to mean the amount they would pay "out of pocket" rather than the actual APC they would be willing to pay from whatever source was available. Our concern stemmed from the fact approximately $20 \%$ of the responses were under $\$ 100$ and over half the responses were less than the amount of the APC the 
author had paid for the article they had published that was the basis for including them in the survey. For this reason we have not pursued further analysis of this question.

\section{[Table 1 about here]}

Journal APC cost analysis - As noted above, the respondents published in 69 journals. Tables 2 and 3 breakdown the journals' APC by discipline and whether or not the journal was listed in the JCR 2009. Please note, the unit of analysis for these tables is the journal, rather than the author. For those journals where the APC was based on the number of pages published, we averaged the APC across the sample of responding authors publishing in the particular journal.

\section{[Tables 2 and 3 about here]}

Source of APC - Tables 4-6 breakdown the source of funding for the APC by discipline category, GNP of the author's country and size of the APC categorized respectively. The respondents were given an opportunity to provide written comments concerning the source(s) that were used for paying the APC. Five authors indicated they did not pay an APC. In tracking down the reason, we found that one of the journals was launched in 2010 and did not start charging APCs until 2011. We inadvertently selected another journal for which the publisher charged APCs for some of their journals but not that particular journal. Nine respondents indicated they used multiple sources to pay these fees. In six cases this involved a mix of personal funds and some other source of institutional funding. There were no other comments we found to be notable or consistent enough to describe.

[Table 4 - 6 about here] 
Choice of Journal - Figure 1 summarized the ratings of the impact of six factors on the authors' decision to publish in the journal they chose. The respondents were given an opportunity to provide written comments concerning the factors influencing their choice of a journal in which to publish. Ten of the comments focused on the authors' difficulty getting the manuscript accepted in other journals. In five of these comments, the authors felt the journal they chose was more willing to accept unusual or non-standard approaches to research/scholarship or presentation formats. Twelve comments focused on the size of the APC as an important factor in selecting a journal to publish their work. Four respondents commented APCs were too high particularly for authors without funding. In addition, three authors replied to the email request to participate via email and in their email complaining about or noting that high APCs were hardship or unfair. Eleven respondents indicated that quality or the journal's impact/dissemination was an important factor. Ten respondents mentioned speed of review/publication, service/support aspects of the journal or good previous experiences publishing in the journal as an important factor. Four respondents indicated the ability to publish color figures, multimedia or lack of page length requirements were important factors in their choice of a journal. Four respondents noted the fact the journal was open access as the major factor in their choice of a journal.

\section{[Figure 1 about here]}

\section{Discussion}

Our survey confirmed the results of previous and studies concerning what factors authors take into consideration when choosing where to submit a 
manuscript. The three most important factors were the fit of the article within the subject area of the journal, the scientific quality of the journal in some cases as measured by the impact factor and the speed of review and publication. The OA status of the journal was slightly less important, although $60 \%$ of the respondents judged this very important of important. One has to bear in mind that this survey was specifically targeted to authors who have recently submitted to and published in an OA journal, in contrast to most earlier studies.

Three journals from the list used in our study can be used to illustrate the role of these factors in the author submission choice. The journal of Medical Internet Research belongs to wider group of electronic only OA journals, often founded in the late 1990s, which focus on the different aspects of the use of the web and thus offers a natural outlet for "papers" in that domain. PLoS Biology in its turn was from the start designed to be top-quality journal and is in fact the number one journal in its subject area, as measured by the impact factor. The service offering of PLoS One has from the start been to provide a very rapid publication cycle combined with the wide dissemination and high quality standards of the publisher in question.

A frequently heard argument against APC funded journals is that they place authors in different positions depending on their possibilities to obtain the funding needed to pay the fee. We found two main factors influencing the financing possibilities, firstly the research discipline and secondly the country of origin of the author. Among our respondents grant financing of APCs is more common in the bio- and physical sciences than in the social sciences and 
humanities. Our results also show that research grants or institutional funds dominate as financing mechanism for journals charging higher APCs, whereas personal funds play a much bigger role in the lower APC brackets (below \$1000). Personal funds are also much more used by authors from lower income countries.

Nicholas and Rowlands (2005) were somewhat surprised that only a minority of the respondents in their study associated OA publishing with a payment model . This could be explained by the fact that OA journals charging APCs were still very rare at the time of the survey in January 2004.

In Swan and Brown's 2004 survey those authors who had published previously in OA journals also reported if and how they had paid a possible APC. Thirty-six percent had not paid a fee at all and for an additional 19\% the fee had been waived by the publisher. Twenty-five percent had paid the fee from their research grant, $8 \%$ from departmental funds and 9\% from other institutional funds. In 4\% of cases the fee was paid by the author (Swan and Brown 2004). Their results indicate a lower degree of direct author funding. One has to bear in mind that their study was done several years ago and that authors views on OA and preferences may have changed in the meantime.

Our results can also be compared to results from the EC-funded SOAP project, which has been carried out in parallel with this study (Dallmeier-Tiessen et al 2011). Our study differs in a number of important ways from the SOAP survey which used massive emailing to authors who had published with some of the 
participating publishers. The survey focused on their attitudes towards Open Access. The response rate was just over $2.5 \%$ of the roughly $1,500,000$ researcher/scholars who received the email. Those respondents who had published in an OA journal answered additional questions. The distribution of the means of financing the APCs roughly corresponded to our results. An important question concerned the ease of obtaining the needed funding and here their study showed substantial differences between disciplines with researchers from the physical sciences having least amount of difficulty with researchers in the social scientists and humanities claiming the highest level of difficulty.

Although journals tend to justify the specific levels of their APC with their costs per published paper (supply side) equally important is the authors 'willingness to pay the APC of a particular journals (demand side). A comparison of the journals included in the study (Table 3) reveals that the level of the APC charged is strongly related to the objective or perceived quality of the journal. $71 \%$ of journals with an ISI impact factor charged more than 1,000 USD whereas the corresponding figure was $15 \%$ for journals without an impact factor. The journals charging the highest APC also have the highest impact factors (Plos Biology APC $=\$ 2,900, \mathrm{IP}=12.9$ and Nucleid Acids Research $\mathrm{APC}=\$ 2,770, \mathrm{IP}=7.4$ ).

Scientific Journal publishing is in a state of change, with Open Access journals rapidly increasing their market share. Most of this growth is occurring in established or newly founded journals using article processing charges to fund operation. For the last few years this growth has, according to Laakso et al (2011), been more or less a linear at round 30\%, but the big question remains if 
this new service model after an initial pioneering stage is reaching the steep incline of the classical adoption curve of innovations. Author attitudes towards paying the required article processing charges and their ability to obtain funding, balanced against the quality of the service they experience, will decide on what the peer reviewed journal looks like in the future.

\section{End Notes}

1. http://wowter.net/2011/01/06/the-impact-factor-of-open-accessjournals/

2. We included all articles published in 2010 in the pilot. One journal, BMC Medical Education, had approximately 100 articles in 2010. We decided the advantaged of a larger sample sized gained by including all the data from these authors outweighed the potential biasing effect.

3. 2009 two-year impact factor.

4. ibid

\section{References}

European Association of Science Editors (2008) EASE statement on inappropriate use of impact factors. Retrieved June 26, 2011 from http://www.ease.org.uk/statements/EASE_statement_on_impact_factors.shtml. 
Bird, C. (2008) Oxford Journals' adventures in open access. Learned Publishing, 21(3), 200-208. doi: 10.1087/095315108X288910

Björk, B-C. \& Holmström, J. (2006) Benchmarking scientific journals from the submitting author's viewpoint. Learned Publishing, 19(2), 147-155

Björk, B-C. \& Öörni, A. ( 2009) A Method for Comparing Scholarly Journals as Service Providers to Authors, Serials Review, 35(2) 62-69.

Dallmeier-Tiessen S., Goerner B., Darby R, Hyppoelae J., Igo-Kemenes P., Kahn D., Lambert S., Lengenfelder A., Leonard C, Mele S., Polydoratou P., Ross D., RuizPerez S., Schimmer R., Swaisland M. \& van der Stelt W. (2010) Open Access Publishing - Models and Attributes. Max Planck Digital Library/Informationsversorgung. 1-62 Retrieved from http://edoc.mpg.de/478647

Dallmeier-Tiessen S., Darby R., Goerner B., Hyppoelae J., Igo-Kemenes P., Kahn D., Lambert S., Lengenfelder A., Leonard C., Mele S., Nowicka M., Polydoratou P., Ross D., Ruiz-Perez S., Schimmer R., Swaisland M. \& van der Stelt W. (2011) Highlights from the SOAP project survey. What Scientists Think about Open Access Publishing, Working paper, arXiv, 28.1.2011 Retrieved from http://arxiv.org/abs/1101.5260v2

Guédon, J.C. (2001) In Oldenburg's Long Shadow: Librarians, Research Scientists, Publishers, and the Control of Scientific Publishing, ARL Proceedings 
138, Association of Research Libraries, Washington D.C. Retrieved from http://www.arl.org/resources/pubs/mmproceedings/138guedon.shtml

Laakso M., Welling P., Bukvova H., Nyman L., Björk B-C. \& Hedlund T. (2011) The Development of Open Access Journal Publishing from 1993 to 2009. PLoS ONE 6(6) e20961. doi:10.1371/journal.pone.0020961.

Nicholas, D. \& Rowlands, I. (2005) Open Access Publishing: The Evidence from the Authors (Guest Editorial), The Journal of Academic Librarianship, Volume 31 (3), pp. 179-181

Nicholas, D \& Huntington, P \& Rowland, I. (2005), Open Access Journal Publishing. The views of some of the world's senior authors, Journal of Documentation, 61(4), pp. 497-519

Nisonger, T. (1999) JASIS and library and information science journal rankings: A review and analysis of the last half-century, Journal of the American Society for Information Science, 50(11), 1004-1019

Schroter, S., Tite, L. \& Smith R. (2006) Open Access publishing and author-pays business models: a survey of authors' knowledge and perceptions, Journal of the Royal Medical Society, 99(3), pp. 141-148

Swan, A. \& Brown, S. (1999) What Authors Want - The ALPSP research study on the motivations and concerns of contributors to learned journals. ALPSP. 
Retrieved from

http://www.alpsp.org/ngen_public/article.asp?id=200\&did=47\&aid=356\&st=\& oaid=-1.

Swan, A. \& Brown, S. (2004) Authors and open access publishing, Learned Publishing 17, 219-224.

Tenopir, C. \& King, D. (2000). Towards electronic Journals - realities for scientists, librarians and publishers, Washington D. C.: Special Libraries Association.

Ware, M. \& Mabe M. (2009) The STM report - An overview of scientific and scholarly journals publishing. International Association of Scientific, Technical and Medical Publishers. pp. 68. Retrieved from http://www.stmassoc.org/2009_10_13_MWC_STM_Report.pdf

Ziobrowski, A. J. \& Gibler, K.M., (2000) Factors Academic Real Estate Authors Consider When Choosing Where to Submit a Manuscript for Publication, Journal of Real Estate Practice and Education 3(1) , 43-54. 
Table 1 Articles published over the last 5 years in different types of journals

\begin{tabular}{crcc}
\hline $\begin{array}{c}\text { Number of articles } \\
\text { Published }\end{array}$ & $\begin{array}{c}\text { Subscription } \\
\text { Journals }\end{array}$ & $\begin{array}{c}\text { OA Journals w/o } \\
\text { APC }\end{array}$ & $\begin{array}{c}\text { OA Journals } \\
\text { with APC }\end{array}$ \\
\hline $\mathbf{0}$ & 14. & $51 \%$ & $17 \%$ \\
$\mathbf{1}-\mathbf{5}$ & $36 \%$ & $38 \%$ & $74 \%$ \\
$\mathbf{6 - 1 0}$ & $22 \%$ & $6 \%$ & $6 \%$ \\
$\mathbf{1 1 - 2 0}$ & $14 \%$ & $3 \%$ & $2 \%$ \\
$\mathbf{2 1 - 3 0}$ & $7 \%$ & $1 \%$ & $1 \%$ \\
$\mathbf{3 0 - 4 0}$ & $4 \%$ & $0 \%$ & $1 \%$ \\
Above 40 & $3 \%$ & $1 \%$ & $0 \%$ \\
\hline \hline
\end{tabular}

Percentages are based on 429 respondents. 


\begin{tabular}{|c|c|c|c|c|c|}
\hline & \multicolumn{4}{|c|}{ APC Category } & \multirow[b]{2}{*}{ Number $^{2}$} \\
\hline & $<500$ & $501-1000$ & $1001-2000$ & 2001-3000 & \\
\hline Agriculture and Forestry & $71 \%$ & $29 \%$ & & & 7 \\
\hline Business and Economics & $71 \%$ & $29 \%$ & & & 7 \\
\hline $\begin{array}{l}\text { Chemistry, Earth Sciences, Physics and } \\
\text { Astronomy }\end{array}$ & $10 \%$ & $50 \%$ & $40 \%$ & & 10 \\
\hline $\begin{array}{l}\text { Education, Social Sciences, Law and } \\
\text { Political Science }\end{array}$ & $13 \%$ & $67 \%$ & $20 \%$ & & 15 \\
\hline $\begin{array}{l}\text { Health Sciences, Biology and Life } \\
\text { Sciences }\end{array}$ & $7 \%$ & $14 \%$ & $50 \%$ & $29 \%$ & 14 \\
\hline $\begin{array}{l}\text { History and Archaeology, Arts and } \\
\text { Architecture, Languages and Literatures }\end{array}$ & & & $100.0 \%$ & & 1 \\
\hline $\begin{array}{l}\text { Technology, Engineering, Mathematic } \\
\text { and Statistics, Computer Science }\end{array}$ & $27 \%$ & $53 \%$ & $20 \%$ & & 15 \\
\hline
\end{tabular}

APC categories are in US Dollars (USD).

Based on the 69 journals in which the responding authors published.

Statistical significance (Fisher's exact) $\mathrm{p}<0.0001$.

The percentages in each cell are for the number (given in the last column) of authors who published articles in that discipline category. 
Table 3 Analysis APC by JCR 2009

\begin{tabular}{ccccccc}
\hline \hline & & \multicolumn{5}{c}{ APC Category } \\
\cline { 3 - 6 } & & $<500$ & $501-\mathbf{1 0 0 0}$ & $\mathbf{1 0 0 1 - 2 0 0 0}$ & $\mathbf{2 0 0 1 - 3 0 0 0}$ & Number \\
\hline \multirow{2}{*}{ JCR 2009 } & No & $35 \%$ & $50 \%$ & $13 \%$ & $2 \%$ & 48 \\
& Yes & $5 \%$ & $24 \%$ & $57 \%$ & $14 \%$ & 21 \\
\hline \hline
\end{tabular}

Based on the 69 journals in which the responding authors published.

The percentages in each cell are for the number (given in the last column) of authors who published articles in that discipline category.

APC categories are in US Dollars (USD).

Journal Citation Report of 2009 (JCR 2009)

Statistical significance (Fisher's exact) $p<0.0001$. 
Table 4 Source of Funding by Discipline Category

\begin{tabular}{|c|c|c|c|c|c|c|c|c|}
\hline & \multicolumn{7}{|c|}{ Source of Funding } & \multirow[b]{2}{*}{ Number } \\
\hline & $\begin{array}{l}\text { Grant or } \\
\text { Contract }\end{array}$ & $\begin{array}{l}\text { National } \\
\text { Funding } \\
\text { (OA Policy) }\end{array}$ & $\begin{array}{l}\text { Institutional } \\
\text { Funding } \\
\text { (OA Policy) }\end{array}$ & $\begin{array}{l}\text { Discretionary } \\
\text { Funds } \\
\text { (Institutional) }\end{array}$ & $\begin{array}{l}\text { Personal } \\
\text { Funds }\end{array}$ & $\begin{array}{c}\text { Fee } \\
\text { Waived }\end{array}$ & Other & \\
\hline Agriculture and Forestry & $23 \%$ & $4 \%$ & $15 \%$ & $4 \%$ & $35 \%$ & $13 \%$ & $7 \%$ & 48 \\
\hline Business and Economics & $10 \%$ & $4 \%$ & $4 \%$ & $23 \%$ & $46 \%$ & $10 \%$ & $2 \%$ & 48 \\
\hline $\begin{array}{l}\text { Chemistry, Earth Sciences, Physics and } \\
\text { Astronomy }\end{array}$ & $30 \%$ & $9 \%$ & $17 \%$ & $11 \%$ & $24 \%$ & $9 \%$ & $3 \%$ & 47 \\
\hline $\begin{array}{l}\text { Education, Social Sciences, Law and Political } \\
\text { Science }\end{array}$ & $17 \%$ & $2 \%$ & $17 \%$ & $21 \%$ & $19 \%$ & $17 \%$ & $6 \%$ & 110 \\
\hline Health Sciences, Biology and Life Sciences & $46 \%$ & $4 \%$ & $10 \%$ & $20 \%$ & $8 \%$ & $8 \%$ & $5 \%$ & 77 \\
\hline $\begin{array}{l}\text { History and Archaeology, Arts and } \\
\text { Architecture, Languages and Literatures }\end{array}$ & $20 \%$ & $20 \%$ & & & & $40 \%$ & $20 \%$ & 5 \\
\hline $\begin{array}{l}\text { Technology, Engineering, Mathematic and } \\
\text { Statistics, Computer Science }\end{array}$ & $24 \%$ & $5 \%$ & $10 \%$ & $32 \%$ & $15 \%$ & $14 \%$ & $1 \%$ & 88 \\
\hline
\end{tabular}

Statistical significance (Fisher's exact) $p<0.001$

The percentages in each cell are for the number (given in the last column) of authors who published articles in that discipline category. 
Table 5 Source of funding by authors' country GNP category

\begin{tabular}{lcc}
\hline \hline & \multicolumn{2}{c}{ Per capital GNP } \\
\cline { 2 - 3 } & $\begin{array}{c}\text { Over } \mathbf{\$ 2 5 , 0 0 0} \\
\text { USD }\end{array}$ & $\begin{array}{c}\text { Under } \mathbf{\$ 2 5 , 0 0 0} \\
\text { USD }\end{array}$ \\
\hline Grant/contract & $31 \%$ & $16 \%$ \\
National Funding (OA Policy) & $5 \%$ & $3 \%$ \\
Institutional Funding (OA Policy) & $10 \%$ & $16 \%$ \\
Discretionary Funds (Institutional) & $26 \%$ & $10 \%$ \\
Personal Funds & $11 \%$ & $39 \%$ \\
Fee Waived & $12 \%$ & $3 \%$ \\
Other & $5 \%$ & $3 \%$ \\
Number & $\mathbf{2 6 2}$ & $\mathbf{1 5 9}$ \\
\hline \hline
\end{tabular}

Statistical significance (Fisher's exact) $p<0.001$.

The percentages in each cell are for the number (given in the bottom row) of authors who published articles in that discipline category. 
Table 6 Source of Funding by Size of APC in USD

\begin{tabular}{lrrrr}
\hline \hline & \multicolumn{4}{c}{ Size of APC in USD } \\
\cline { 2 - 5 } & $<\mathbf{5 0 0}$ & $\mathbf{5 0 1 - 1 0 0 0}$ & $\mathbf{1 0 0 1 - 2 0 0 0}$ & $\mathbf{2 0 0 1 - 3 0 0 0}$ \\
\hline Grant/contract & $17 \%$ & $23 \%$ & $30 \%$ & $67 \%$ \\
National Funding (OA Policy) & $4 \%$ & $4 \%$ & $4 \%$ & $14 \%$ \\
Institutional Funding (OA Policy) & $8 \%$ & $12 \%$ & $17 \%$ & $7 \%$ \\
Discretionary Funds (Institutional) & $17 \%$ & $20 \%$ & $24 \%$ & $7 \%$ \\
Personal Funds & $35 \%$ & $26 \%$ & $6 \%$ & \\
Fee Waived & $17 \%$ & $12 \%$ & $11 \%$ & $7 \%$ \\
Other & $3 \%$ & $3 \%$ & $8 \%$ & \\
Number & 109 & $\mathbf{1 6 7}$ & $\mathbf{1 3 2}$ & $\mathbf{1 5}$ \\
\hline \hline
\end{tabular}

${ }^{1}$ Statistical significance (Fisher's exact) $p<0.001$.

The percentages in each cell are for the number (given in the bottom row) of authors who published articles in that discipline category. 


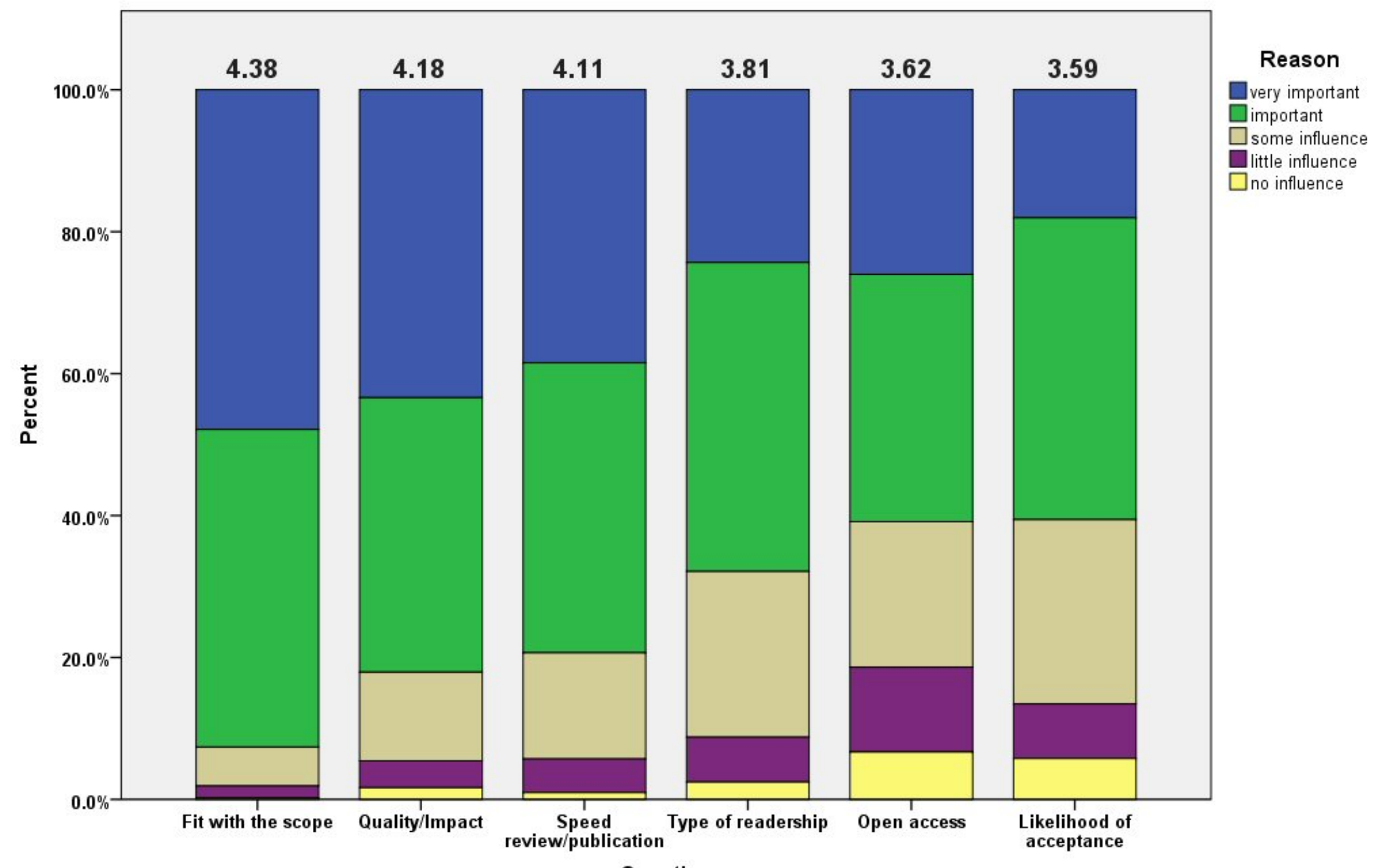

\section{Question}

